\title{
Electric and electromagnetic investigation of a karst system
}

\author{
Marion P. Miensopust ${ }^{1}$, Jan Igel ${ }^{1}$, Thomas Günther ${ }^{1}$, Raphael Dlugosch ${ }^{1}$, and \\ Sarah Hupfer ${ }^{1}$ \\ ${ }^{1}$ Leibniz Institute for Applied Geophysics, Hannover, Germany
}

\section{Motivation}

Dissolution of rocks such as anhydrite, gypsum, limestone, dolomite or salt rock enlarges fractures or pore space and finally results in voids and cavities within karst rocks. Especially in populated areas such collapses may have catastrophic consequences, but the current knowledge about the evolution, governing processes and capabilities of prediction are insufficient. Geophysical methods can contribute to the understanding, first of all by detailed investigation of known sinkhole structures and - later on - by monitoring areas of high risk as well as localising those areas before a surface expression is visible. As voids and cavities are often fluid- or air-filled (or both) and the electrical properties of the fluid and air are in many cases significantly different to those of the surrounding karst rocks, electric and electromagnetic methods such as, e.g., electrical resistivity tomography (ERT), ground-penetrating radar (GPR) and nuclear magnetic resonance (NMR) are potentially useful tools for the investigation of sinkhole structures. In the case study presented here we focus on the application of electric and electromagnetic methods on the karst system of the Innerste Mulde in Lower Saxony which is surface-mapped by numerous sinkhole structures.

\section{Geological Setting}

The Innerste Mulde is a trough structure along the northern rim of the Harz Mountains in Northern Germany. It comprises steeply dipping, jointed Pläner limestone of Turonian age which host a karst water system bound to this limestone of the western flank of the Innerste Mulde. The subsurface karst system is about $27 \mathrm{~km}$ long and can be traced on surface by numerous sinkholes and collapse structures. Close to the village of Altwallmoden an anticline (i.e., the Lutterer Sattel) extends into the Innerste Mulde and causes steepening of the stratification and hence a narrowing flow channel of the karst system. Therefore, a part of the water emerges in karst springs near Altwallmoden, the remaining water reappears in the springs of Baddeckenstedt further north (Knolle \& Jacobs, 1988).

The so-called Kirschensoog (Figure 1) is an elongated elliptic sinkhole structure of approximately $75 \mathrm{~m}$ length and $20 \mathrm{~m}$ width. It is one of the karst springs near Altwallmoden. At the southern end the base of the spring is about $5 \mathrm{~m}$ below the surrounding surface and flattens towards the north. It only temporarily yields water, e.g., in times of snow melting or after heavy rain fall.

In February and early March 2015, the Kirschensoog itself and also the discharging brook were water filled. Towards mid March the water level dropped quickly and the brook 

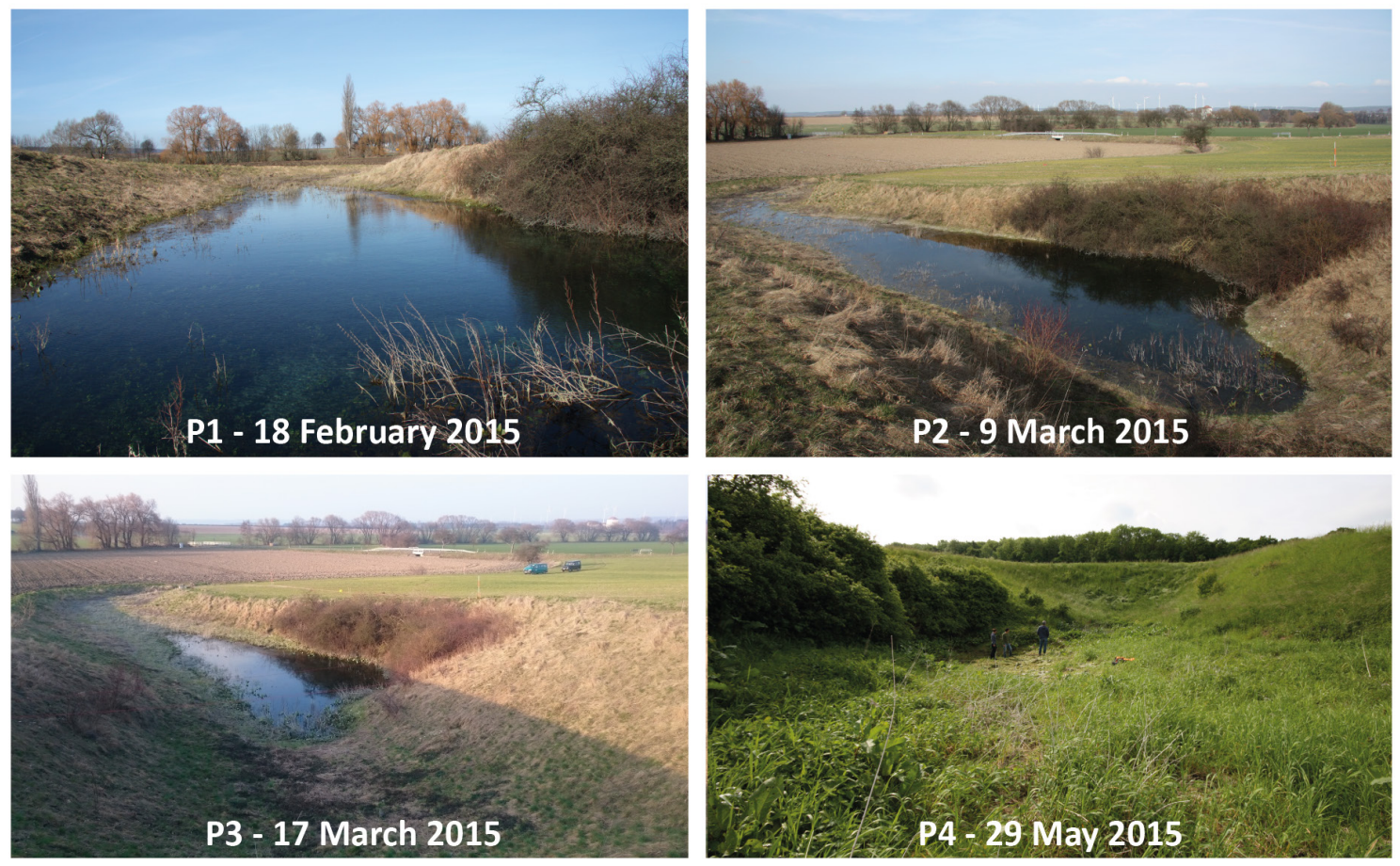

Figure 1: Temporary karst spring Kirschensoog. Water level changed visibly within a few days and first the discharge and later the spring itself fell dry. Viewing directions are indicated in Figure 2.

and large parts of the Kirschensoog fell dry. In May, the entire trough was completely dry. Figure 1 shows the spring at different water levels. The feeding system of this spring is still under speculation but obviously the spring acts like a pressure relief valve of the subsurface karst water system which might go along with larger water-filled cavities in the surrounding.

\section{$3 \quad$ Field Studies}

Figure 2 shows the location of the Kirschensoog and the positions of the ERT and GPR profiles as well as the 2D survey setups for surface NMR (SNMR). In total, ERT data were acquired along four profiles using Wenner-alpha and Wenner-beta electrode arrays with 140 electrodes and $2 \mathrm{~m}$ electrode spacing. Figure 3 shows inversion results of all four ERT profiles stitched together. The resistivity models show 3D structures and dipping features. The obtained resistivity of the limestone seems rather low suggesting possible fluid- or clay-filled fissures and fractures. Additional field and laboratory studies are required to confirm or disprove this interpretation.

Three ERT profiles and one additional profile were also investigated using GPR with antenna frequencies from 20-400 MHz. The covering soil causes strong attenuation and, therefore, restricted the penetration depth of the signal. Figure 4 shows an example of $200 \mathrm{MHz}$ GPR data where the cover layer is thin (approx. less than $0.5 \mathrm{~m}$ ). The dipping reflectors - coinciding with the dipping features of the ERT models - are possibly related to the bedding of the limestone or fluid-filled fractures. To determine the dipping direction 


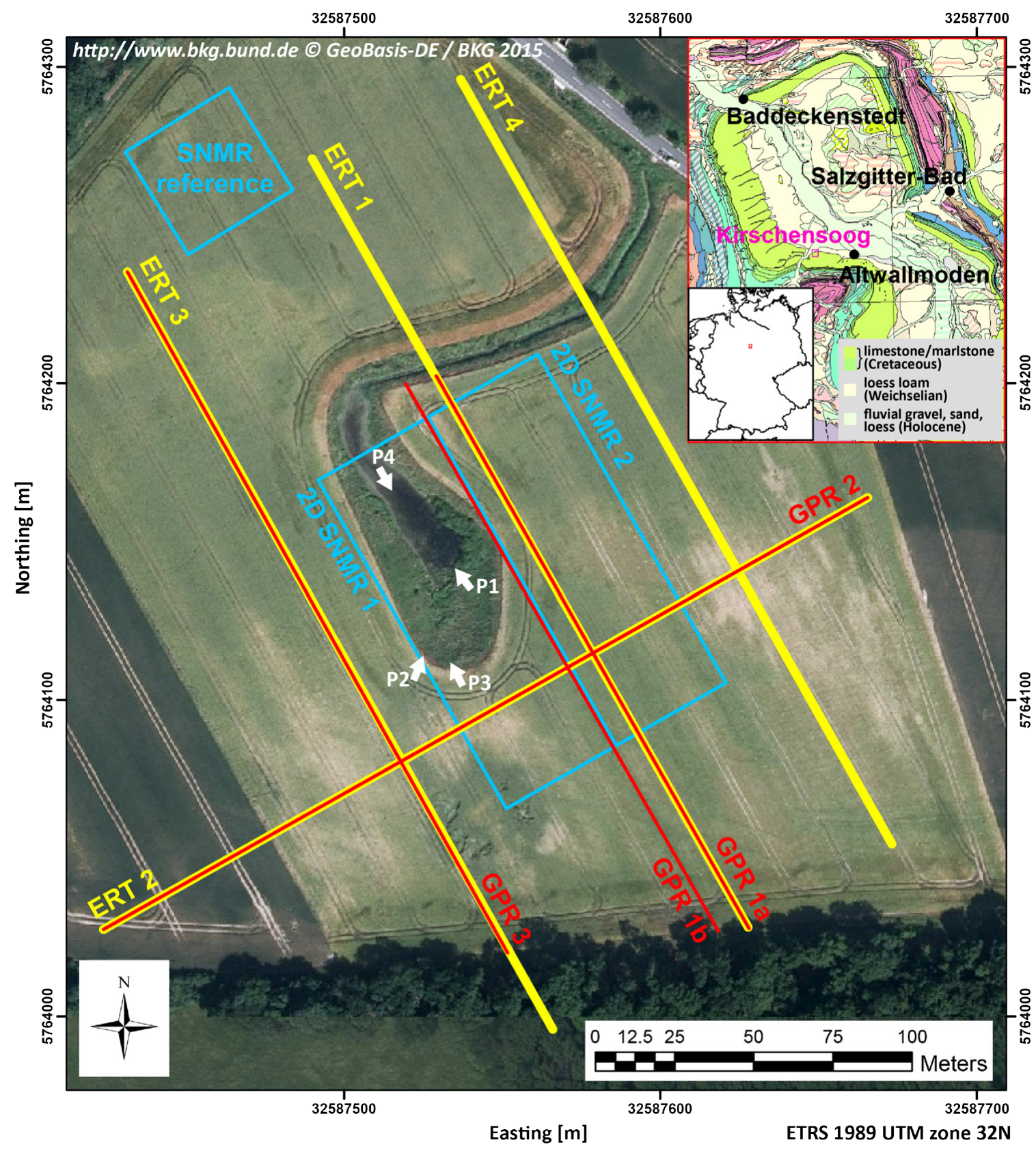

Figure 2: Survey area (magenta rectangle on geological map) and locations of ERT (yellow) and GPR (red) profiles as well as 2D SNMR survey setups (blue). White arrows P1 - P4 indicate approximate viewing directions of the pictures in Figure 1. Inlay: Geological map (NIBIS map service of LBEG) - shown area is indicated as red rectangle on the small map of Germany. 


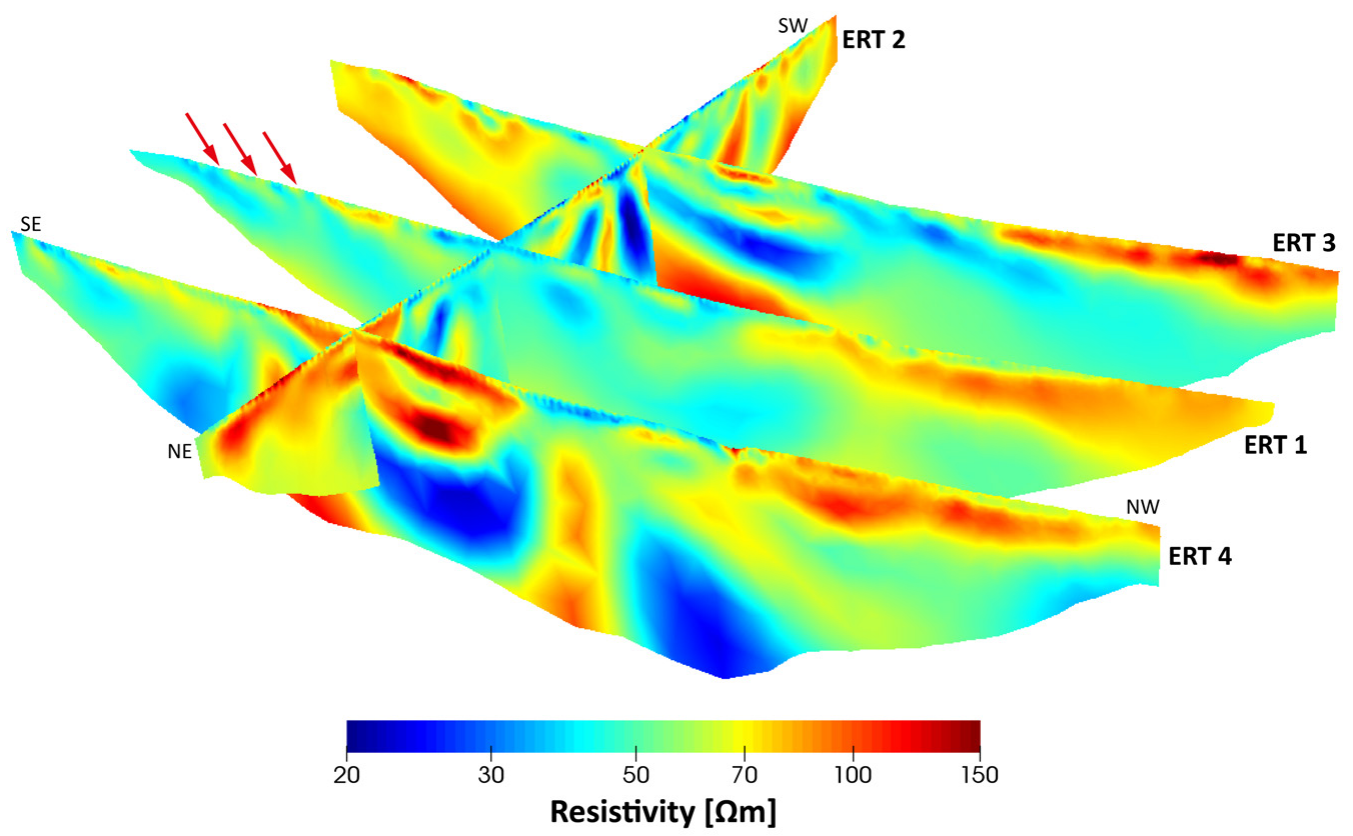

Figure 3: Resistivity models based on 2D inversion of four ERT profiles using BERT (Günther et al., 2006). Topography was considered during inversion as well as both Wenner-alpha and Wenner-beta data. Red arrows exemplarily indicate dipping structures (also seen as reflectors in GPR data - Figure 4).

additional measurements are required (e.g., focused 3D GPR measurements).

2D SNMR surveys were conducted (above and east to the karst spring) according to a loop layout suggested by Jiang et al. (2015), i.e., using a $120 \mathrm{~m} \times 40 \mathrm{~m}$ transmitter loop while recording simultaneously at six overlapping $40 \mathrm{~m} \times 40 \mathrm{~m}$ receiver coils and one reference loop (for noise cancellation). No signal of free water could be observed. Hence, if the spring is fed by a large-scale (several meters in each dimension) water-filled cavity, it must be either located further away from the karst spring or in greater depths (several tens of meters or more) or both as deducted from synthetic studies.

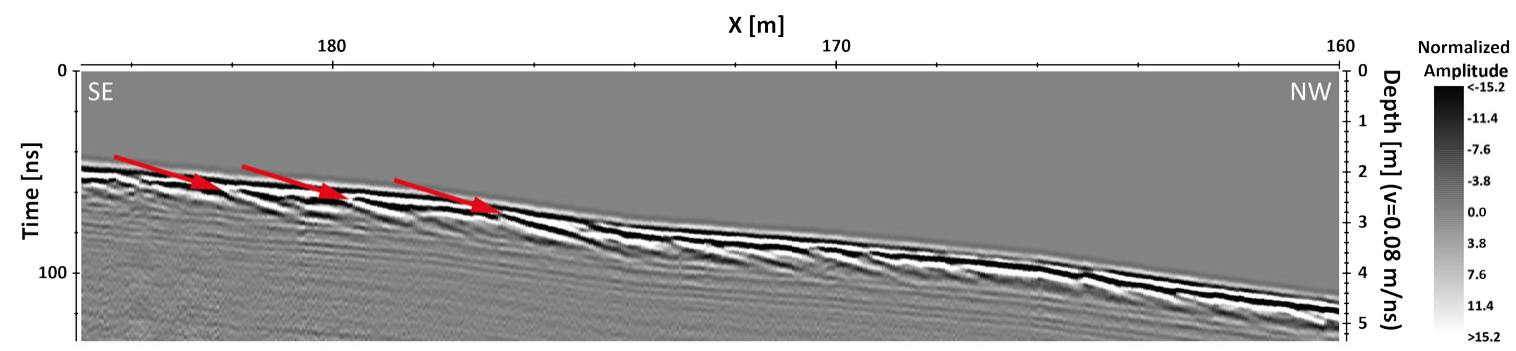

Figure 4: GPR data (200 MHz; SE end of profile GPR 1a; processed using REFLEXW (Sandmeier, 2014)) shows dipping reflectors (exemplary indicated by red arrows; also seen in resistivity models - Figure 3) in areas of thin soil cover. 


\section{Laboratory Studies}

Soil and rock samples were taken for laboratory analysis to complement the field data and support their interpretation. The soil samples of the clay-rich cover layer were subject to three types of laboratory measurements. Firstly, laboratory 4-point-resistivity measurements resulted in approximately $20 \Omega \mathrm{m}$ (about $50 \mathrm{mS} / \mathrm{m}$ ) which is common for clay-rich soil. Secondly, the dielectric spectroscopy revealed a wave attenuation of about $50-60 \mathrm{~dB} / \mathrm{m}$. This confirms the results of TDR probe measurements in the field and explains the limited depth of investigation using GPR. And finally, laboratory NMR (Figure 5 bottom right; green line) only detected very little free but mostly claybound water. But the latter cannot be detected in the field by surface NMR.
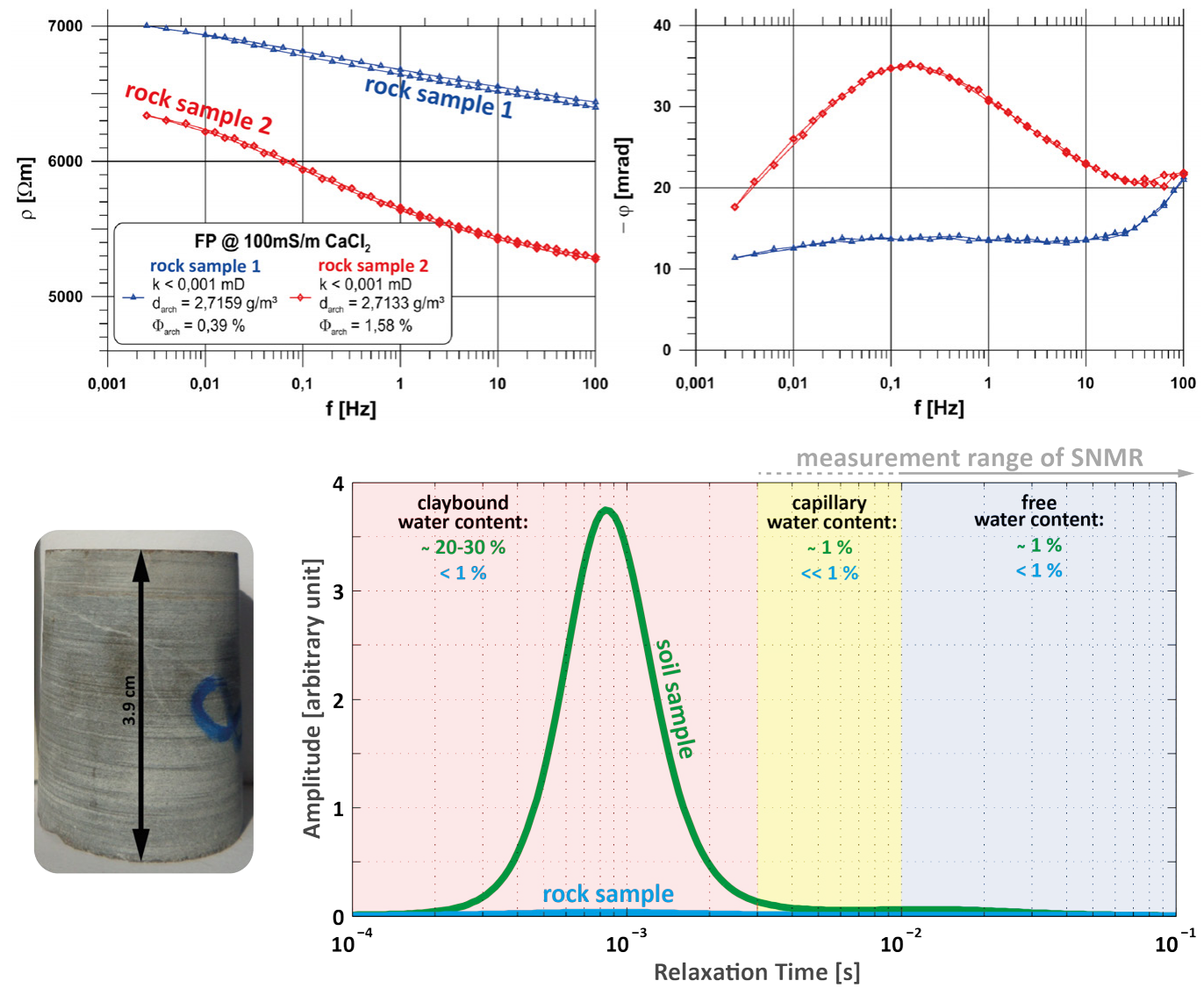

Figure 5: Laboratory results. Top: IP spectra of two saturated limestone samples with electrical resistivity (left) and phase shift (right) in dependence on frequency f. The related petrophysical results namely hydraulic permeability k, Archimedean density $\mathrm{d}_{\text {arch }}$ and Archimedean porosity $\Phi_{\text {arch }}$ of both samples are specified. Bottom left: Limestone sample from survey area. Bottom right: Exemplary NMR relaxation time distributions of a soil sample with in-situ moisture content (green) and a saturated rock sample (cyan). Values for claybound, capillary and free water content were deducted based on measurements of three soil and five rock samples.

The rock samples were also analysed by different laboratory methods. Only very little water - less than $1 \%$ of free and claybound water - were detected by laboratory NMR (Figure 5 bottom right; cyan line). Pycnometer and permeameter studies showed that 
the limestone samples are dense rocks with little porosity and low permeability. Spectral induced polarisation (IP) measurements (Figure 5 top) showed very high resistivities $(>5000 \Omega \mathrm{m})$ suggesting that the rock samples are very dense. At the same time there is a distinct phase maximum observed at $\mathrm{f}=0.2 \mathrm{~Hz}$ which is rather unusual for dense rocks.

\section{Interpretation and Outlook}

The dipping structures obtained in the resistivity models as well as in the GPR data are possibly related to the bedding of limestone or fissures/fractures. The rather low in-situ resistivity might be an indication of disruption and presence of fluids or clay-filled fractures. On the other hand, SNMR observed no signal of capillary nor free water and, therefore, a large-scale water-filled cavity in close proximity of the spring in shallow depth can be excluded. But it is still unclear why the resistivity of the limestone obtained in the field is significantly lower compared to the laboratory results. Is the studied sample representative for the formation? Can those differences be explained solely by rock moisture? Further measurements and analyses are needed to enhance understanding. For example, a focused high resolution 3D ERT and GPR investigation of an area with thin soil cover might be useful to obtain detailed information about the bedding and fissure system of the limestone. Furthermore, additional measurements at different targets within this karst system are intended, e.g. close to a deep not-filled sinkhole with steep edges (offering outcrop information to support interpretation) or in between individual sinkholes within a closely spaced sequence (looking for possible causes of the aligned appearance of the sinkholes at this location).

\section{Acknowledgements}

We would like to thank Robert Meyer and Dieter Epping for their support during the fieldwork and Cynthia Minnich and Markus Loewer for the dielectric spectroscopy of the soil samples. We very much appreciate the permission and concessions by Konrad Wolf to measure on his land.

\section{References}

Günther, T., Rücker, C., \& Spitzer, K.(2006). 3-D modeling and inversion of DC resistivity data incorparating topography - Part II: Inversion. Geophysical Journal International, $166(2), 506-517$.

Jiang, C., Müller-Petke, M., Lin, J., \& Yaramanci, U. (2015). Magnetic resonance tomography using elongated transmitter and in-loop receiver arrays for time-efficient 2-D imagging of subsurface aquifer structures. Geophysical Journal International, 200(2), 824-836.

Knolle, F., \& Jacobs, F.(1988). Die Karstgrundwassergewinnung am nördlichen Harzrand (Niedersachsen, Bundesrepublik Deutschland) und ihre Gefährdung. Die Höhle, 39(3), 81-89.

Sandmeier, K.-J. (2014). REFLEXW 7.5 - Windows 9x/NT/2000/XP/7/8- program for the processing of seismic, acoustic or electromagnetic reflection, refraction and transmission data. (manual) 